advanced period of life is of necessity more or less inefficient, and any inducement for a medical practitioner to continue in office under such circumstances by the fear of a pension not being granted on resignation is without doubt seriously disadvantageous not only to the ratepayers but specially so to the sick poor.

Compulsory Medical Certification of Cause of Death. No greater mistake in legislation was, in the opinion of many Poor-law medical officers, ever made than when following the Scotch example, this became compulsory in England. Cases are constantly met with in practice where the medical officer is called in just previous to death, not really to give medical attendance, but to give the necessary certificate after death. It is now very difficult for him to refuse, and so, rather than face a coroner's jury, with the liability to censure, if sufficient cause of death is established by post-mortem examination, the certificate is often given. Formerly, when this was optional, much good resulted from the refusal to give it. The idea is now very prevalent that the required certificate must be given, and this idea is not far from being correct.

\section{ANNUAL MEETING OF THE ASSOCIATION} AT NEWCASTLE-UPON-TYNE, 1893.

THE sixty-first annual Meeting of the British Medical Association will be held at Newcastle-upon-Tyne, beginning on Tuesday, August 1st, and lasting until the end of the week.

\section{General Arrangements.}

Dr. G. H. Philipson, Profess $3 r$ of Medicine in the University of Durham, and Senior Physician to the Royal Infirmary, Newcastle-upon-Tyne, will be the President. The addresses and' Section $*$, as will be seen from the detailed programme, are arranged in the usual way. It will, however, be noticed that there is a Section in anatomy and physiology, one in otology, and another in dermatology.

The service on the first day of the meeting will be held in the ancient church of St: Nicholas, now a cathedral.

\section{The College Boildings.}

The business of the meeting will be conducted in the new and handsome buildings of the University of Durham College of Medicine, and of the Durham College of Science, which have been lent for the occasion. The Colleges are conveniently near to each other, they are centrally situated, and they will afford ample accommodation for the Sections and the general business of the meeting. The museum will be made a special feature. The commercial part will be placed in the chemical laboratory of the College of Science, alarge, lofty, and beautiful room. The microscopical and pathological divisions will be put into other rooms. The examination hall at the College of Medicine will probably be rised as the reception room.

Hospitals.

In addition to the Royal Infirmary, a large general hospital, there are several special hospitals in Newcastle which will be open to the inspection of members of the association. The new Fever Hospital can also be seen.

Hotels and Travelling.

The hotel accommodation is excellent, and those who prefer to stay at the seaside or in the country can readily do so. The rooms occupied by the students at University' College, Durham, will be available for members of the Association duritig the week. The railway service in the district is good, both on the main and on the local lines. Tramways have been laîd by the corporation throughout the town on a regular system.

Excursions.

There are many places of interest in the district to which excursions can be made-for instance, Alnwick Castle, Cragside at Rothbury, the Roman Wall with the excavations at the Chesters, Holy Island, Bamborough, etc. The district abounds in antiquities, the old Norman keep, parts of the ancient walls and gates of Newcastle, the Roman Wall, Tynemouth Priory, Fenkle Abbej, and the abbey at Durham. In contrast to these are the works and factories which cover the banks of the Tyne, and members who are interested in shipbuilding, engine works, chemical works, ordnance foundries, etc., will find plenty to interest them. Of coal pits there is no lack.

Short excursions will probably be made down the river to Tynemonth, South Shields, to the curious rocks at Marsden and also out to sea. On the Friday afternoon it is proposed to hold a special convocation at Durham for the conferring of honorary degrees, and this will no doubt be followed by a reception or garden party in the Castle.

In addition to its Town Moor, Newcastle is well off for public parks. The most beautiful is the Armstrong Park, where it is hoped the Mayor may give a garden party.

When the meeting is over, members may be tempted to run across to the English lakes, to go to Scotland, or to sail for Norway in one of the five vessels leaving the Tyne for that. country.

\section{ACUTE POISONING CAUSED BY TINNED OX TONGUE.}

BY EDMUND GWYNN, M.D., Medical Officer of Health, Hampstead.

A Freshly opened tinned ox tongue was placed before $M r . X$ his wife, and two children for breakfast on November 14th, 1892. Upon carving the tongue, Mr. $X$ perceived an unusual appearance and odour, and stopped Mrs. $X$ and the younger child, aged 4 years, from eating the portions already served to them ; they had only just tasted it. Mr. $\mathrm{X}$ then divided an omelette with the fork that he had used in carving the tongue. About noon on the same day the younger child was seized in the street with uncontrollable vomiting and purging, and was brought home in a state of collapse. Soon afterwards Mrs. X had severe abdominal pain, violent sickness, and purging, and fell upon the floor in a state of collapse, dejecta running from her. The elder child, aged 6 , was sick in the afternoon, and $\mathrm{Mr}$. $\mathrm{X}$ felt sick towards evening, and became faint, with cold sweats. These two latter had not tasted the tongue, but had eaten the omelette which had been divided by the infected fork.

The family attendant, Dr. W. Boulting, to whom I am indebted for the foregoing particulars, found Mrs. $X$, upon his arrival, cold and pulseless, vomiting occasionally and complaining of giddiness; the diarrhœa continued for some days, and left tenderness in the abdomen, with pain upon pressure over the right side. The child, aged 4 , fell into a profound stupor, from which she could not be roused for some hours.

Dr. Boulting further informs me that Mrs. X (eight days after the attack) still continues ill ; directly she attempts to eat solids she has increased pain and passes blood. At first the temperature was subnormal-in the evening of the first day $99.5^{\circ}$; afterwards normal or slightly below normal. The others ultimately recovered in a day or two.

I found the tongue to be soft, wet, pappy in parts, dull in colour, with an absence of the jelly which is generally found in these tins. The microscope showed portions of it to be much decomposed, and the muscular fibres to be quite broken up. The tongue was submitted to Mr. H. W. Stokes for analysis, who pronounced it to be a most virulent and highly poisonous sample of tinned meat. The meat was saturated with salts of iron due to the corrosion of the containing tinned iron vessel caused by the action of the decomposing meat on the vessel. No other metal could be detected. As evidence of its great poisonous power Mr. Stokes's assistant, "to see what it was like," took a piece not larger than a shilling; in five hours he was seized with violent vomiting, diarrhoea, and giddiness, the vomiting recurring for thirty hours afterwards.

There are several points of interest in the above cases: (1) The extremely minute quantity of infective matter that affected Mr. X and his child, which could only have been derived from the fork that had been used to divide the omelette : (2) the number of hours (eight) that intervened before Mr. X became affected; (3) the great resemblance which the attack bore to an outbreak of choleraic diarrhcea; indeed, had cholera been epidemic or near the neighbourhood at the time, much alarm might have been occasioned. 